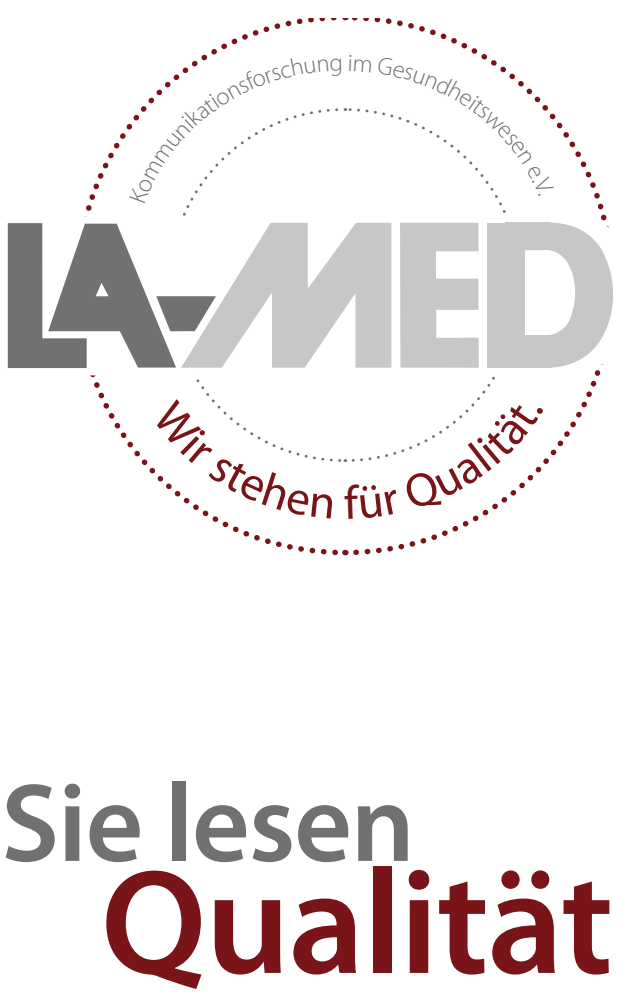

Damit das auch so bleibt,

befragen wir Sie in

Kooperation mit tns infratest

in den nächsten Wochen.

Ihr Urteil ist uns wichtig.

Bitte nehmen Sie teil!

\title{
Migräne führt nicht zu kognitiven Störungen
}

Bei Patienten mit schwerer Migräne mit Aura und häufigen Attacken kommt es in der Kernspintomografie nicht selten zu Marklagerveränderungen in T2-betonten Schichten und zu klinisch stummen Insulten. Diese könnten theoretisch zu einer vaskulären Enzephalopathie und einer vaskulären Demenz prädisponieren. Eine Arbeitsgruppe aus Boston ging dieser Frage nach.

- Die Basis dieser Studie bildete die Women's Health Study. Diese große Studie rekrutierte zwischen 1992 und 1995 insgesamt 39876 Frauen, die im Gesundheitsbereich arbeiteten und 45 Jahre oder älter waren. Die Studie selbst war als eine Therapiestudie zur Wirksamkeit von Acetylsalicylsäure und Vitamin E im Vergleich zu Placebo zur Prävention kardiovaskulärer Ereignisse und maligner Erkrankungen angelegt.

Im Jahr 1998 wurde eine kognitive Substudie gestartet. In diese Studie wurden Frauen aufgenommen, die 65 Jahre oder älter waren. Die insgesamt 6377 Teilnehmerinnen unterzogen sich einer neuropsychologischen Testbatterie und wurden dann im Abstand von zwei Jahren mindestens zweimal nachuntersucht.

Für diese Analyse standen Daten von 6349 Frauen zur Verfügung. Davon berichteten 853, unter einer Migräne zu leiden. 195 hatten eine Migräne mit Aura, 248 eine Migräne ohne Aura. 410 Frauen gaben an, in der Vergangenheit eine Migräne gehabt zu haben. Im Vergleich zu Frauen ohne Migräne bestanden keine Differenzen bezüglich kognitiver Funktionen in der Baseline und auch keine Veränderungen über die Zeit hinweg.

Frauen, die unter einer Migräne leiden, unterscheiden sich bezüglich kognitiver Funktionen und Veränderungen kognitiver Funktionen über die Zeit nicht von Frauen, die keine Migräne haben.

- P. M. Rist et al.

Migraine and cognitive decline among women: prospective cohort study. BMJ 2012;345: e5027. Epub 2012/08/10

\section{Kommentar}

Diese Substudie der großen Women's Health Study reproduziert die Ergebnisse anderer großer Register oder weiterer prospektiver Studien, die ebenfalls keinen Zusammenhang zwischen dem Vorliegen einer Migräne und dem Auftreten kognitiver Störungen fanden. Diese Erkenntnisse sind für die klinische Praxis wichtig. Viele Patientinnen sind sehr beunruhigt, wenn sie vom Radiologen mitgeteilt bekommen, dass in ihren Kernspintomografien "weiße Flecken" zu sehen sind. Dies wird von Allgemeinradiologen häufig als entzündliche Erkrankung des ZNS oder als zerebrale Mikroangiopathie interpretiert.

H. C. DIENER —

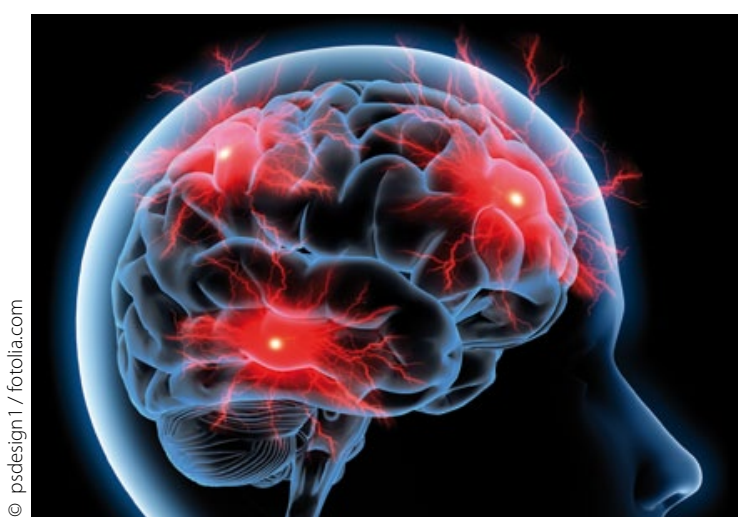

